\title{
Mechanical characteristic variation of ballastless track in high- speed railway: effect of train-track interaction and environment loads
}

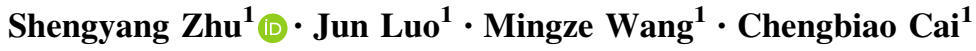

Received: 23 September 2020/Revised: 4 November 2020/Accepted: 6 November 2020/Published online: 30 November 2020

(C) The Author(s) 2020. This article is published with open access at Springerlink.com

\begin{abstract}
Due to the fact that ballastless tracks in highspeed railways are not only subjected to repeated traintrack dynamic interaction loads, but also suffer from complex environmental loads, the fundamental understanding of mechanical performance of ballastless tracks under sophisticated service conditions is an increasingly demanding and challenging issue in high-speed railway networks. This work aims to reveal the effect of train-track interaction and environment loads on the mechanical characteristic variation of ballastless tracks in high-speed railways, particularly focusing on the typical interface damage evolution between track layers. To this end, a finite element model of a double-block ballastless track involving the cohesive zone model for the track interface is first established to analyze the mechanical properties of the track interface under the loading-unloading processes of the negative temperature gradient load (TGL) followed by the same cycle of the positive TGL. Subsequently, the effect of wheel-rail longitudinal interactions on the nonlinear dynamic characteristics of the track interface is investigated by using a vehicle-slab track vertical-longitudinal coupled dynamics model. Finally, the influence of dynamic water pressure induced by vehicle dynamic load on the mechanical characteristics and damage evolution of the track interface is elucidated using a fluid-solid coupling method. Results show that the loading history of the positive and negative TGLs has a great impact on the nonlinear development and distribution of the track interface
\end{abstract}

Shengyang Zhu

syzhu@swjtu.edu.cn

1 Train and Track Research Institute, State Key Laboratory of Traction Power, Southwest Jiaotong University, Chengdu 610031, China stress and damage; the interface damage could be induced by the wheel-rail longitudinal vibrations at a high vehicle running speed owing to the dynamic amplification effect caused by short wave irregularities; the vehicle dynamic load could produce considerable water pressure that presents nonlinear spatial-temporal characteristics at the track interface, which would lead to the interface failure under a certain condition due to the coupled dynamic effect of vehicle load and water pressure.

Keywords Ballastless track · High-speed railway · Mechanical characteristic · Interface damage · Train-track interaction - Temperature gradient - Dynamic water pressure $\cdot$ Cohesive zone model

\section{Introduction}

With the advantages of strong stability, high smoothness and less maintenance, ballastless tracks for high-speed railways overcome the disadvantages of ballasted track, and have become the prior selection to enabling a rapid development of high-speed railways worldwide [1, 2]. However, it is still quite difficult for ballastless tracks to avoid some typical damage and faults during its service time, attributed to the fact that they are exposed to the complicated loads of high-speed train dynamic load and environmental loads such as temperature change and rain water erosion. Meanwhile, due to the diversity of their constituent materials and the complexity of inter-layer connection, the service performance of ballastless tracks is found to be deteriorating in practical engineering 
applications, with main defects of the interface damage or cracks between track layers, as shown in Fig. 1. Usually, the temperature load is the main cause of the initiation of the interface damage which will be then accelerated by train dynamic loads. Subsequently, the rainwater will be inevitably trapped at the interface gap to produce dynamic water pressure under train dynamic load, leading to the aggravation of the interface damage.

The interface damage could be quite harmful to the track and train systems through complicated mechanisms. Firstly, the emergence and development of the interface damage will lead to the gradual destruction of the integrity of the track system; especially after the penetration of rain water, it will have a splitting and scouring effect on the track interface under train dynamic loads, which will intensify the expansion of the interface gap to the depth, and cause the ballastless track to gradually lose its bearing capacity, thus affecting the stability and durability of the track structure. Secondly, the change of interface bonding state will result in the alteration of load transfer mechanism of ballastless tracks. The interface bonding area will continue to decrease due to the emergence of the interface damage, and the vehicle-track interaction load will be more concentrated in the middle of the track, causing the subgrade to bear unfavorable concentrated loads. Thirdly, the interface damage weakens the stiffness, strength and stability of the track system, leading to an increased dynamic displacement of rails under spatial train dynamic loads, which could even exceed the standard limit and finally pose a threat to the running safety of high-speed trains. For example, a field investigation of a high-speed railway found that the maximum amount of the interface gap can reach up to more than $10 \mathrm{~mm}$, and under the condition of continuous abnormal high temperature in summer, 141 interface gaps appeared in some sections of ballastless

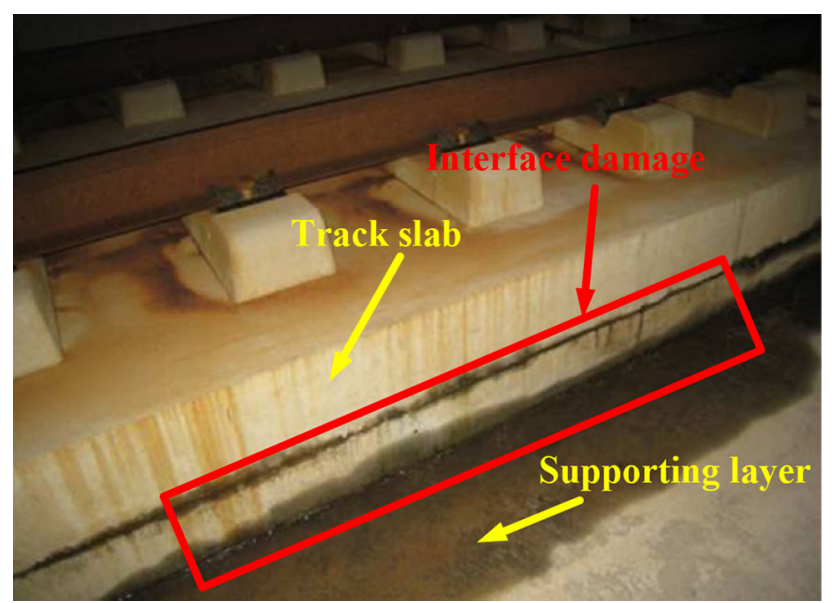

Fig. 1 Example of interface damage of a ballastless track in China's high-speed railways tracks on this high-speed railway line [3]. This occurrence of the interface gaps affected the safety operation of highspeed trains, leading to speed limit treatment and widespread trains delay. Therefore, the effect of train-track interaction and environment loads on the mechanical characteristics of ballastless track interface is very sophisticated, which is one of main concerns to improve the design theory and maintenance technology of ballastless tracks, and to ensure the operation safety of high-speed railways.

To capture the mechanical characteristic variation of ballastless tracks under environment loads such as the temperature load, Zhong et al. [4] established a three-dimensional finite element model of slab track to study the deformation and interface stress of a slab track under daily changing temperature. Zhang et al. [5] tried to improve the mechanical properties of cement asphalt (CA) mortar and concrete composite specimens in high-speed railway by modifying the interfacial bonding relationship, and discussed the effects of temperature on the mechanical properties. Peng et al. [6] carried out pull-off tests to study the interfacial bonding strength between CA mortar and concrete slab, and found that temperature cycles decrease the interfacial bonding possibly due to the weakened mechanical interlocking forces at the interface. Wang et al. [7] evaluated the mechanical performance of the CA mortar of the slab track interlayer under extreme temperatures, by conducting the flexural strength and fatigue tests and a transient thermal simulation. Yu et al. [8] presented an in situ experiment to evaluate the influence of seasonal temperature variations on the curling behavior of concrete track slab, and created a thermomechanical coupled finite element model to compare with the experimental data. Chen et al. [9] studied the effect of acid rain environment on the degradation of CA mortar at track interface in practical engineering; they found that one of the main reasons for the material degradation is the loss of asphalt and asphaltenes under the coupled effects of loads and rain. Cai et al. [10] investigated the arching mechanism of slab joints under high temperature conditions considering the buckling instability of track structure, and the damage process of joint concrete and its effects on the arching instability were analyzed with the help of the field investigation. Li et al. [11] established a three-dimensional finite element model of the CRTS II track incorporating a cohesive zone model to simulate the nonlinear behavior of the track interface under the temperature gradient load (TGL). Zhu et al. were among the first that introduced the cohesive zone model to investigate the interface damage of slab tracks under temperature and vehicle dynamic loads [12], and further they obtained the damage constitutive model of the concrete interface of double-clock ballastless track based on experimental tests, with which the interface 
damage evolution of the track under monotonic and cyclic TGL was investigated to elucidate the practical application of the proposed model [13]. However, few studies can be found that focus on the simulation analysis of the track interface damage under the alternative action of negative and positive TGLs.

Concerning on the mechanical property of the concrete interface of ballastless tracks subject to train dynamic loads, much work has been done. Ren et al. [14] built a slab track model based on the damage mechanics to study the effect of debonding on the concrete damage distribution and mechanical responses of track slabs, where the rail supporting forces obtained from in situ tests were adopted as the train loads. Zhao et al. [15] carried out a prototype fatigue test for a slab track considering the coupled effects of wheel load, temperature change, and water erosion, in which the repeated wheel loads were applied through a loading vehicle equipped with eccentric vibrator wheels, the TGL was generated by heating or cooling the slab track system, and the water erosion effect was simulated in the test. Zhang et al. [16] established a viscoelastic finite element model of a slab track incorporating viscoelastic parameters and a cohesive zone; the model was verified by experimental data and used to analyze the initiation mechanism of debonding under coupling actions of temperature and dynamic vehicle loadings. Xiao et al. [17] proposed a method for analyzing inter-layer defects in slab tracks under train and temperature loads based on fatigue analysis and the extended finite element method. Cao et al. [18] studied the interface damage mechanism of a slab track under the coupling effect of vehicle dynamic load and the interface water pressure, and investigated the effects of load characters, water viscosity, and crack shape on the coupled hydro-mechanical fracture of the slab track. Zhu et al. [19] developed a coupled dynamics model of a vehicle and the slab track involving nonlinear springdamper elements for simulation of the interface damage. By considering the random nature of the interface damage parameters, the probability analysis was performed using the response surface method and Monte Carlo simulations, and finally the damage assessment criterion and the corresponding safety threshold were suggested on the basis of the concept of reliability for the long-term dynamic performance of slab tracks. However, most of the existing researches only considered the effect of vertical vehicle dynamic load on the mechanical behavior of the track interface, while the coupling effect of the longitudinal and vertical dynamic loads on the interface damage was rarely ascertained because of the complexity of train and track interaction.

In this work, to reveal the mechanical characteristic variation and damage evolution at the track interface between track layers of ballastless tracks in high-speed railway, a cohesive zone model considering mixed-mode damage is employed to investigate the nonlinear mechanical characteristics and damage evolution of the track interface subject to complicated environment loads and vehicle-track interaction load. Firstly, a finite element model of a double-block ballastless track involving the cohesive zone model is established to analyze the effect of loading-unloading processes of the negative and positive TGLs on the mechanical behavior of the track interface. Then, a vehicle-slab track vertical-longitudinal coupled dynamics model is adopted to capture the effect of wheelrail longitudinal interactions on the nonlinear dynamic characteristics of the track interface. Finally, the coupled dynamic effect of vehicle load and water pressure on the mechanical characteristics and damage evolution of the track interface is revealed using a fluid-solid coupling method. Some interesting and useful conclusions are drawn from the comprehensive numerical analysis, which may provide theoretical support for the maintenance strategy establishment and safe operation management of ballastless tracks in high-speed railways.

\section{Constitutive model of the track interface}

For simulating the nonlinear mechanical behavior of the track interface, the cohesive zone model could be an optimal selection as it is widely used in the interface damage analysis of composite structures with different kinds of constitutive relationship forms such as the bilinear, rectangular, trapezoidal, polynomial, and exponential cohesive zone models [20-24], in which the bilinear cohesive zone model has been successfully employed in evaluating the interface damage development of ballastless tracks due to its appropriate modeling for nonlinear damage behavior of the track interface. In this paper, the bilinear cohesive zone model considering mixed-mode damage is employed for investigating the nonlinear mechanical characteristics and damage evolution of the track interface subject to complicated environment loads and vehicle-track interaction load, as shown in Fig. 2.

It is shown in Fig. 2 that under external loads, the stress in the cohesive zone of the crack tip increases linearly with an increase in the displacement, and when the stress reaches its peak value, it will undergo a softening process because of the interface damage initiation. As the displacement continues to increase, the stress decreases linearly, resulting in a decrease in the load-bearing capacity and a gradual expansion of the interface crack. When the stress is reduced to zero, the interface crack grows completely leading to the failure of the interface.

The nonlinear constitutive relationship of the bilinear cohesive zone model can be expressed as 
$\mathrm{t}_{i}=\left\{\begin{array}{ll}t_{i}^{0} \frac{s_{i}}{s_{i}^{0}} & \left(s_{i} \leq s_{i}^{0}\right) \\ t_{i}^{0} \frac{s_{i}^{\mathrm{f}}-s_{i}}{s_{i}^{\mathrm{f}}-s_{i}^{0}} & \left(s_{i}>s_{i}^{0}\right)\end{array} \quad i=\mathrm{n}, \mathrm{s}, \mathrm{t}\right.$,

where subscript $i=\mathrm{n}, \mathrm{s}, \mathrm{t}$ stands for the normal and two shear directions, respectively; $t_{i}$ represents the interface stress under mixed loading modes of tension and shear, respectively, and $s_{i}$ the corresponding interface displacement; $t_{i}^{0}$ represents the peak value of the interface stress under a pure mode of tension or shear, and $s_{i}^{0}$ the corresponding interface displacement; when the cohesive element at the interface completely fails, the interface displacement attains its maximum value $s_{i}^{\mathrm{f}}$.

The interface damage is assumed to be initiated when the following equation satisfies

$\left\{\frac{\left\langle t_{\mathrm{n}}\right\rangle}{t_{\mathrm{n}}^{0}}\right\}^{2}+\left\{\frac{t_{\mathrm{s}}}{t_{\mathrm{s}}^{0}}\right\}^{2}+\left\{\frac{t_{\mathrm{t}}}{t_{\mathrm{t}}^{0}}\right\}^{2}=1$.

To quantitatively describe the damage degree at the interface, a scalar damage variable $D$ that monotonously increases from 0 to 1 is introduced in the numerical analysis. The damage scalar proposed by Camanho and Davila [25] is used to describe the nonlinear softening process, expressed as

$D=\frac{s_{\mathrm{m}}^{\mathrm{f}}\left(s_{\mathrm{m}}^{\max }-s_{\mathrm{m}}^{0}\right)}{s_{\mathrm{m}}^{\max }\left(s_{\mathrm{m}}^{\mathrm{f}}-s_{\mathrm{m}}^{0}\right)}$,

where $s_{\mathrm{m}}^{\max }$ refers to the maximum value of the effective displacement attained during the loading history, $s_{\mathrm{m}}^{0}$ is the effective displacement at the damage initiation, and $s_{\mathrm{m}}^{\mathrm{f}}$ denotes the effective displacement at the complete failure of a material point, which can be obtained as [25]

$s_{\mathrm{m}}=\sqrt{\left\langle s_{\mathrm{n}}\right\rangle^{2}+s_{\mathrm{s}}^{2}+s_{\mathrm{t}}^{2}}$.

After the interface damage initiation, the stress components for the bilinear cohesive zone model can be calculated as

$\left\{\begin{array}{l}t_{\mathrm{n}}=(1-D) k_{\mathrm{n}} s_{\mathrm{n}} \quad s_{\mathrm{n}}>0 \\ t_{\mathrm{s}}=(1-D) k_{\mathrm{s}} s_{\mathrm{s}} \\ t_{\mathrm{t}}=(1-D) k_{\mathrm{t}} s_{\mathrm{t}}\end{array}\right.$,

where $k_{\mathrm{n}}, k_{\mathrm{s}}$ and $k_{\mathrm{t}}$ are the interface stiffness in the normal and two shear directions, respectively.

The energy-based damage evolution law is a rule that each uniaxial damage is combined according to a certain relationship by which the proportion of the normal and shear damages in the cohesive zone are determined quantitatively. The energy dissipated with the development of damage, namely the fracture energy, can be used to properly define the interface damage evolution, which is equal to the area enclosed by the stress-displacement curve under the current stress state. In this regard, the energy-based power law, where the mixed mode damage is determined by the combination of the critical fracture energies (normal and shear) according to the power law, is employed in this work, and thus the track interface failure at a material point under mixed-mode conditions is governed by

$\left\{\frac{G_{\mathrm{n}}}{G_{\mathrm{n}}^{\mathrm{C}}}\right\}^{\alpha}+\left\{\frac{G_{\mathrm{s}}}{G_{\mathrm{s}}^{\mathrm{C}}}\right\}^{\alpha}+\left\{\frac{G_{\mathrm{t}}}{G_{\mathrm{t}}^{\mathrm{C}}}\right\}^{\alpha}=1$,

where $G_{\mathrm{n}}, G_{\mathrm{s}}$, and $G_{\mathrm{t}}$ refer to the work done by the stress and its corresponding relative displacement in the normal and the two shear directions, respectively; $G_{\mathrm{n}}^{\mathrm{C}}, G_{\mathrm{s}}^{\mathrm{C}}$, and $G_{\mathrm{t}}^{\mathrm{C}}$ refer to the critical fracture energy in the normal and the two shear directions; and the power $\alpha$ is set to 2 in the analysis. When the material point fails completely, the mixed-mode critical fracture energy is equal to the sum of each uniaxial fracture energy. It is worth pointing out that under mixed-mode loading the interface failure could occur even if the fracture energy, such as the $G_{\mathrm{n}}$, is smaller than the critical fracture energy $G_{\mathrm{n}}^{\mathrm{C}}$ in the uniaxial state. In this case, the normal stress-displacement curve no longer presents a bilinear relationship when shear displacements appear in the cohesive zone, but it is enveloped in the bilinear curve under a pure normal loading mode, as shown in Fig. 2. Moreover, with the increase in the proportion of shear fracture energy with respect to the total fracture energy, the normal stress-displacement relationship is further and further from the bilinear relationship while closer to the abscissa axis. It can be also known from Eq. (6) that under mixed-mode loading the fracture energy in one direction must be smaller than its corresponding critical fracture energy.

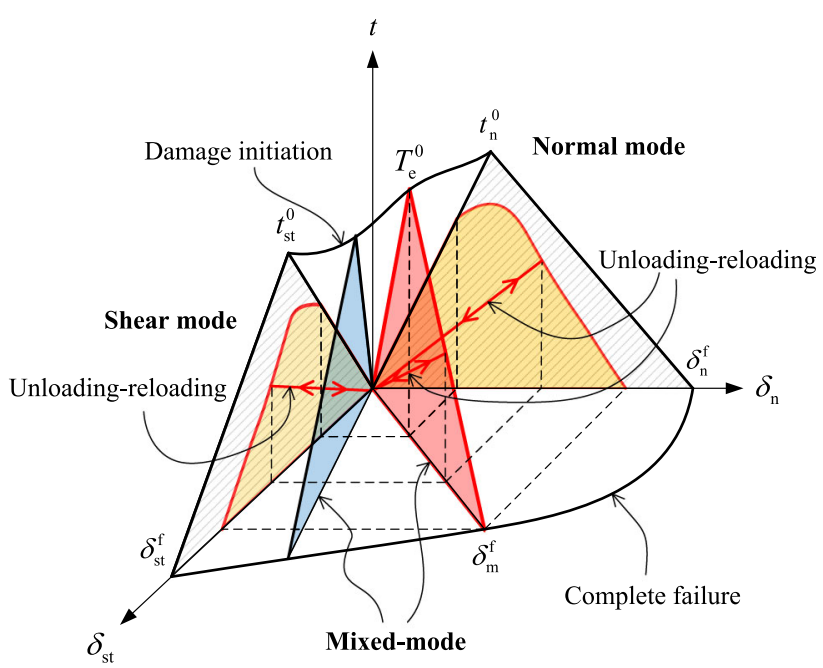

Fig. 2 Bilinear cohesive zone model considering mixed-mode damage 


\section{Effect of temperature loads on mechanical property of track interface}

It is known that the temperature difference between upper and lower surfaces of ballastless tracks could be formed under the action of solar radiation and heat convection due to their poor heat conduction performance, which will generate the TGL along the thickness direction of the track. A higher surface temperature of the track slab will form a positive TGL, resulting in an arching deformation of the track slab, whereas a lower surface temperature of the track slab produces the negative TGL, leading to an unwarping deformation of slab edges. When the bonding strength of ballastless track interlayers is less than the stress caused by the temperature-induced deformation, cracks would be initiated at the track interface and expand along the interface under train dynamic loads and finally form the track slab void, which will significantly affect the service life of ballastless tracks.

Ballastless tracks will experience the repeated processes of loading and unloading of the negative TGL, and followed by the same cycle of the positive TGL. However, most previous studies just focused on the effect of the negative temperature gradient on the interface damage evolution, ignoring its unloading process and the following loading of the positive TGL.

\subsection{Finite element model of double-block ballastless}

In this section, the double-block ballastless track widely used in Chinese high-speed railways is taken as the research subject. To analyze the mechanical characteristics of the track interface under a cyclic variation of TGLs, a finite element model of the track involving the cohesive zone model for the track interface is established using Abaqus software, as shown in Fig. 3. The model is mainly composed of the track slab, the cohesive layer, and the supporting layer, while the rails and fasteners are omitted due to their negligible influence on the track slab deformation. For the heat conduction analysis, the track slab is modeled with the element DC3D8, and the cohesive layer and supporting layer are not involved in the analysis. The thermodynamic parameters of the track system can be referred to in Ref.[12]. For the mechanical analysis, the element C3D8R is adopted for modeling the track slab and supporting layer, and the element COH3D8 with zero thickness is used to simulate the cohesive interface. The "Tie" constraint is used between the cohesive layer and its adjacent layer, and the contact relationship is applied between the track slab and the supporting layer. Symmetric constraints are applied to both ends of the model. Through numerical tests, the mesh size of the track slab and supporting layer is determined to be $0.1 \mathrm{~m} \times 0.1 \mathrm{~m} \times 0.1 \mathrm{~m}$, and it is $0.05 \mathrm{~m} \times 0.05 \mathrm{~m}$ for the cohesive layer, which could eliminate the influence of the mesh size effect. The calculation length of the track is $10 \mathrm{~m}$, and the other common size and material parameters can be found in Ref.[13]. Elastic support constraints are applied to the bottom of the supporting layer to simulate the elastic subgrade. The subgrade stiffness has a significant effect on the track deformation, which is selected as $310 \mathrm{MPa} / \mathrm{m}$ according to a field test in a high-speed railway. The parameters for the cohesive zone model are listed in Table 1, which were determined by conducting splitting loading tests on composite specimen. In the current simulation, the maximum negative/positive TGL are selected according to the code for design of high-speed railway [26], and the temperature gradient loading process is shown in Fig. 4.

\subsection{Stress and damage distribution at track interface}

Figures 5 and 6 show the interface stress and damage distributions along the transverse direction of the track under cyclic temperature loads, respectively, where three loading states including the maximum negative temperature gradient $\left(\mathrm{TGL}=-76.9^{\circ} \mathrm{C} / \mathrm{m}\right)$, the complete unloading $\left(\mathrm{TGL}=0{ }^{\circ} \mathrm{C} / \mathrm{m}\right)$, and the maximum positive temperature gradient $\left(\mathrm{TGL}=90{ }^{\circ} \mathrm{C} / \mathrm{m}\right)$ are plotted together. Since the interface stress, damage and displacement do not change along the longitudinal direction of the track, their contour results are not shown here for brevity.

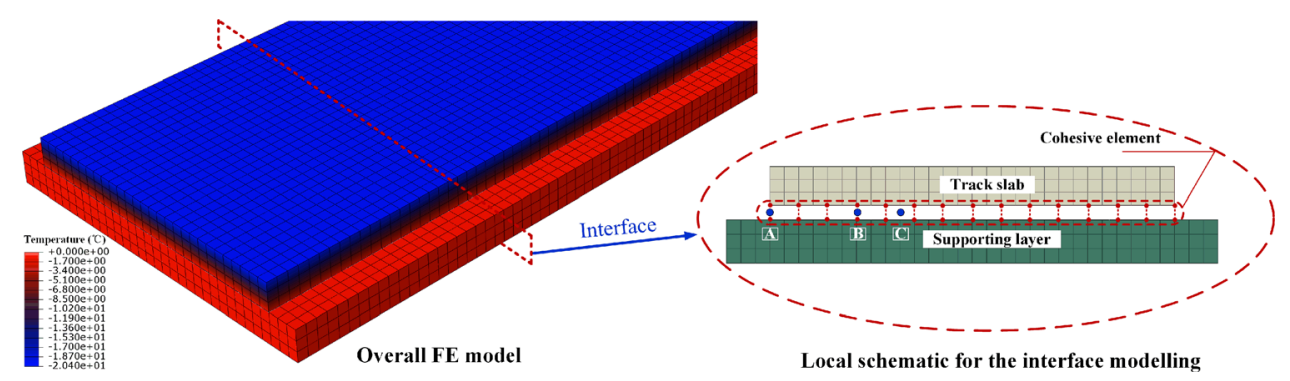

Fig. 3 Finite element model of double-block ballastless track involving the cohesive zone model for the track interface 
Table 1 Parameters for the cohesive zone model

\begin{tabular}{llllrr}
\hline Parameters & $t_{i}^{0}(\mathrm{MPa})$ & $\delta_{i}^{0}(\mathrm{~mm})$ & $k_{i}(\mathrm{~Pa} / \mathrm{m})$ & $\delta_{i}^{\mathrm{f}}(\mathrm{mm})$ & 0.0075 \\
\hline Normal direction $(i=\mathrm{n})$ & 1.43 & 0.0010 & $1.4 \times 10^{12}$ & 5.4 \\
The first shear direction $(i=\mathrm{s})$ & 0.36 & 0.0026 & $1.4 \times 10^{11}$ & 0.0110 & 2.0 \\
The second shear direction $(i=\mathrm{t})$ & 0.36 & 0.0026 & $1.4 \times 10^{11}$ & 0.0110 & 2.0 \\
\hline
\end{tabular}

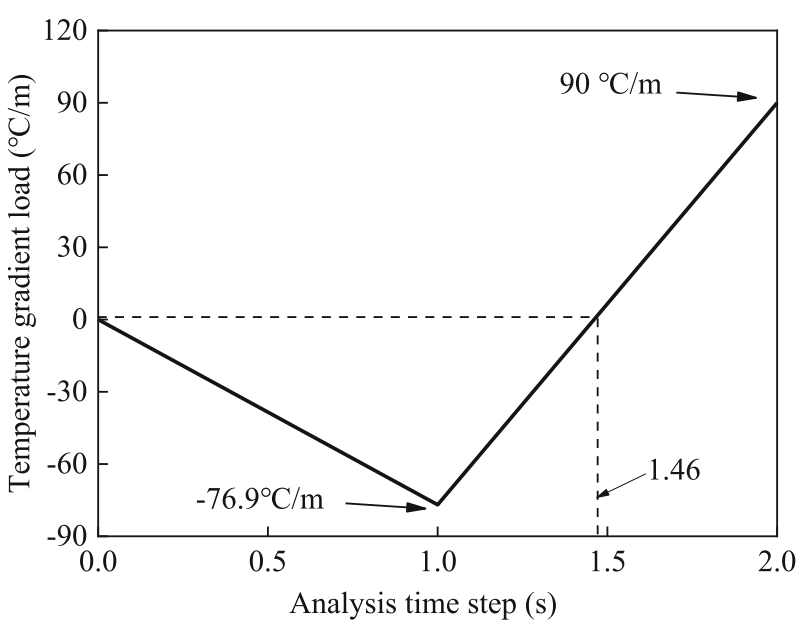

Fig. 4 Loading process of TGL

It can be seen that with the unloading of the negative TGL, the interface stress decreases gradually and it reduces to zero when the negative TGL is completely unloaded, but the interface damage continues to increase. Subsequently, with a gradual increase in the positive TGL, the track slab presents an arching deformation, and the normal and shear contact stresses are generated due to the contact between the track slab edges and the supporting layer. As the previous loading-unloading process of negative TGL has

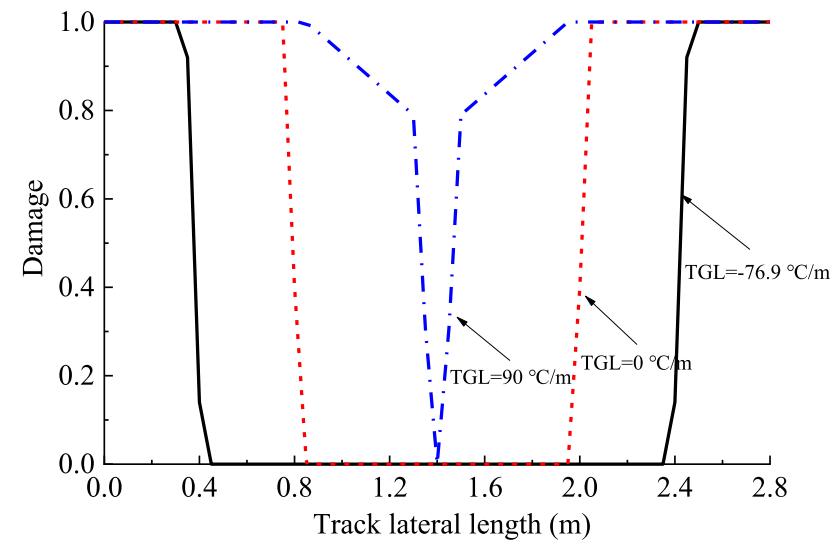

Fig. 6 Interface damage distribution along the lateral direction of the track under the cyclic temperature load

formed a considerable crack length at the interface, the undamaged area in the middle of the track suffers a large interface stress under the arching deformation of the track, which leads to the propagation of the interface crack under the positive TGL. According to the simulation calculation, when there is no damage at the interface, the same positive TGL just causes the interface damage to emerge within around $0.05 \mathrm{~m}$ from the slab edge without forming any cracks. This indicates that the ability to resist interface

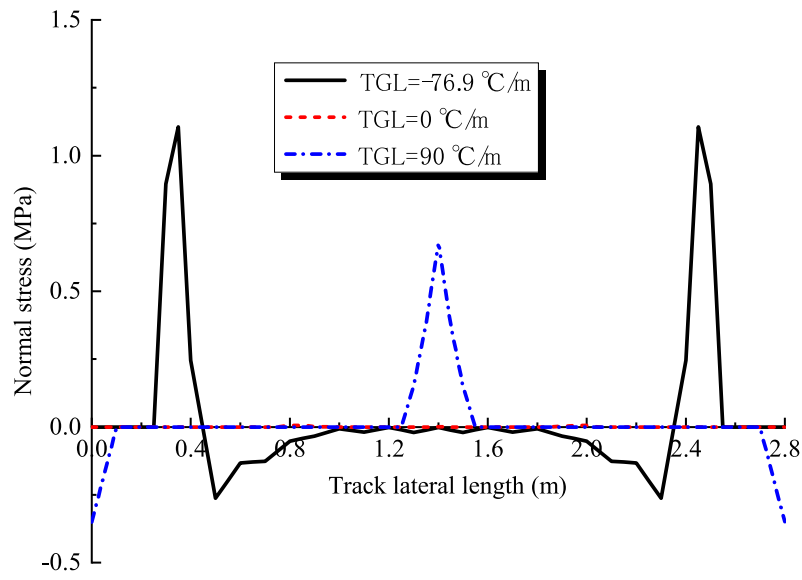

(a)

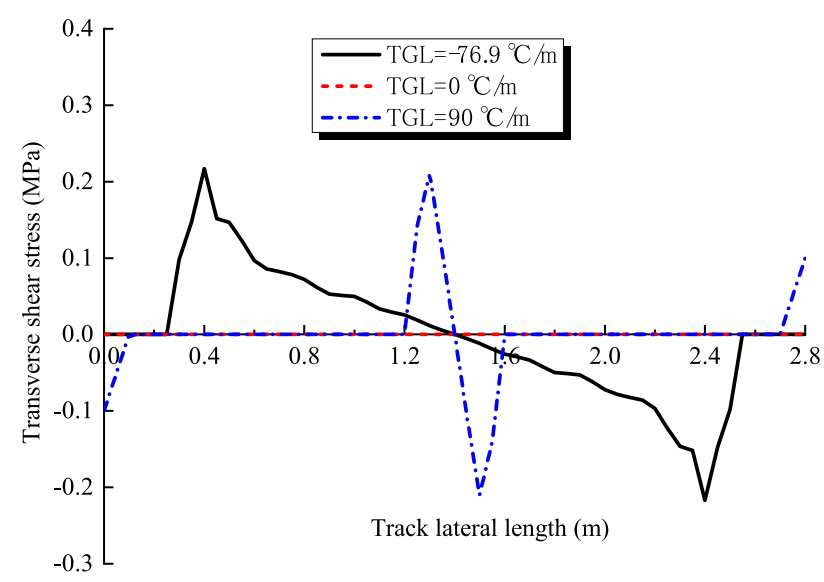

(b)

Fig. 5 Interface stress along the lateral direction of the track under the cyclic temperature load: a normal stress and $\mathbf{b}$ lateral shear stress 


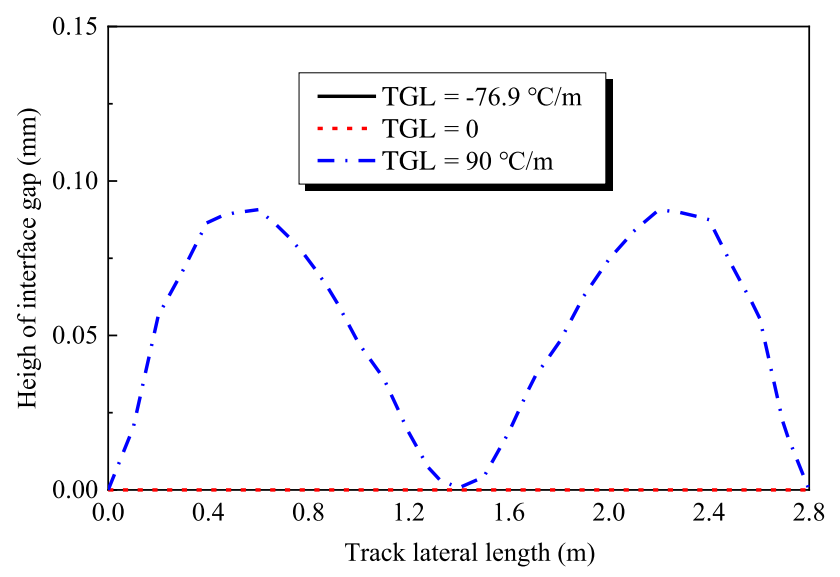

(a)

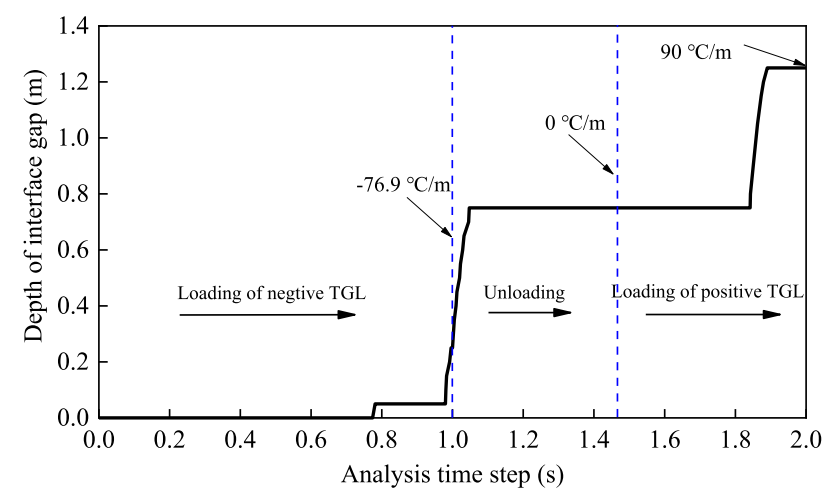

(b)

Fig. 7 Interface gap variation between the track slab and supporting layer under the cyclic TGL: a height of interface gap and $\mathbf{b}$ depth of interface gap

damage and cracking under the positive TGL is greatly reduced after the interface separation.

As shown in Fig. 7a, with the variation of the TGLs, the height of the interface gap firstly decreases and then increases, while the depth of the interface gap increases substantially. Also, the shape of the track interface gap under the negative TGL is quite different from that under the positive TGL, which presents, respectively, a warping curve on both sides of the track slab and a "void" form under the slab. Figure $7 \mathrm{~b}$ shows the depth variation of the interface gap with the changing of TGLs. When the negative TGL is unloaded from the maximum value, the interface gap does not close immediately, but expands rapidly until the negative TGL drops to $-69^{\circ} \mathrm{C} / \mathrm{m}$. Subsequently, the depth of the interface gap keeps unchanged until the positive TGL reaches $64^{\circ} \mathrm{C} / \mathrm{m}$, and it continues to expand and stops at $72{ }^{\circ} \mathrm{C} / \mathrm{m}$. Clearly, the depth variations of the interface gap under different TGLs exhibit strong nonlinear characteristics, and the TGL of track slabs at these "steep slope" sections should be avoided in practical applications in order to prevent the rapid development of the track interface damage.

\subsection{Nonlinear mechanical characteristics of the track interface}

The stress, displacement and damage laws at different positions of the track interface (as shown in Fig. 3) are discussed here during loading and unloading of one cycle TGL.

Figure 8 shows the nonlinear variation of the interface normal stress and displacement with the changing of the TGLs, and the interface damage evolution is shown in Fig. 9. In the loading stage of the negative TGL, the point A is subjected to tensile stress until the interface cracking occurs, and its normal displacement gradually increases with the increase in unwarping deformation of the track slab, while it starts to close slightly after the unloading of the negative TGL. With the increase in the positive TGL, the point A keeps in contact with the supporting layer and generates the contact stress. For the mechanical variation at the point $\mathrm{B}$, it bears the compressive stress under the negative TGL, but it suddenly changes into the tensile stress within a small change of TGL and generates the interface damage during the unloading process. The damage process is quite fast which reflects the characteristic of brittle material fracture, whereas the displacement of the point $\mathrm{B}$ increases gradually under the loading of the positive TGL due to the arching deformation of the track slab. The point $\mathrm{C}$ is located in the middle of the track interface, and its damage occurs under the positive TGL. Its normal displacement is always zero until the damage initiation, and it starts to increase due to the arching deformation of the track slab, which has a similar growth trend with the point $\mathrm{B}$.

The variation characteristics of transverse shear stress and displacement under the cyclic TGL are shown in Fig. 10. It is clearly shown that the shear stress closer to the middle of the track interface is found to be larger than other locations. Note that the shear displacement undergoes a reverse phenomenon when the TGL shifts from negative load to positive load. This is because the track slab produces warping deformations under the negative TGL, whereas the slab generates arching deformation under the positive TGL.

\section{Effect of vehicle-track interaction on the interface mechanical characteristics}

Speed adjustment of the motor cars of high-speed train is usually achieved by traction or braking operations. Especially in mountain high-speed railways such as Sichuan- 


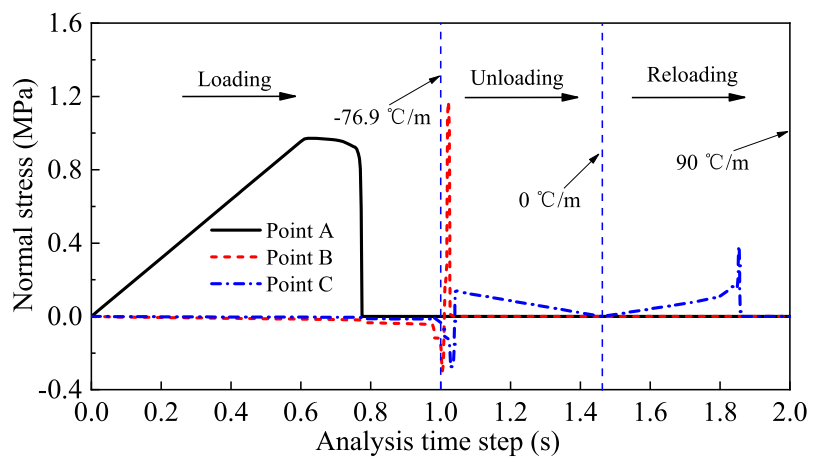

(a)

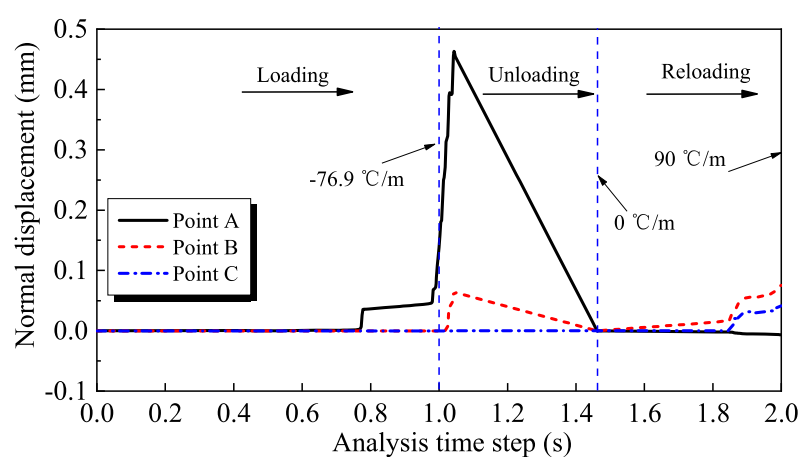

(b)

Fig. 8 Nonlinear mechanical variation of the track interface with the changing of the TGLs: a normal stress, and $\mathbf{b}$ normal displacement

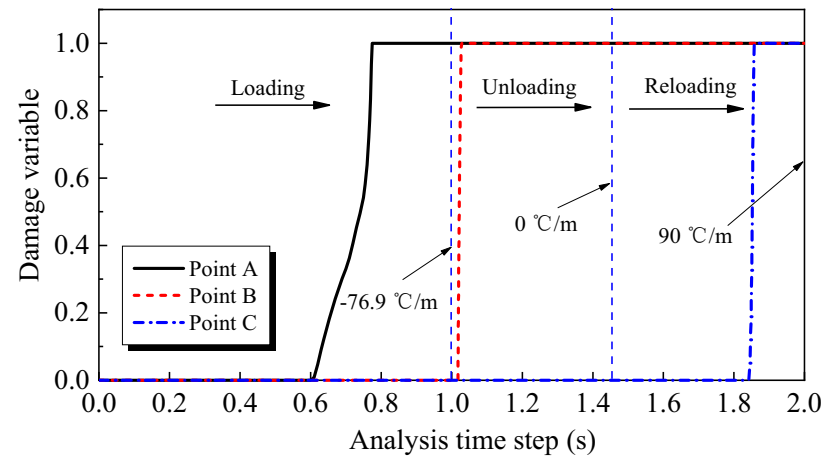

Fig. 9 Damage evolution of the track interface with the changing of the TGLs

Tibet railway that have complex and large gradient sections, the wheel-rail longitudinal interactions may become more intense leading to longitudinal impacts on the track structures. By introducing system longitudinal vibrations and implementing the interface interactions into the classical vehicle-track system, the effect of vehicle-track interaction on the interface mechanical characteristics is presented in this section.

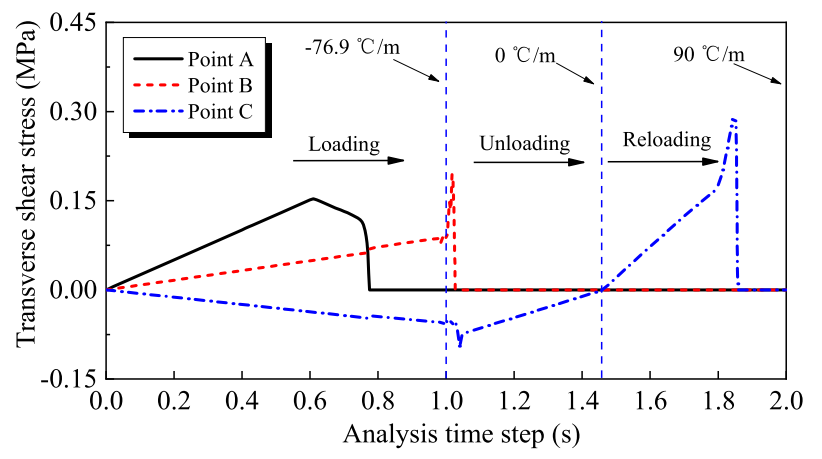

(a)

\subsection{Vehicle-track vertical-longitudinal coupled dynamics model considering interface interactions}

In this section, the CRTS II slab track in high-speed railway is taken as an example to elucidate the effect of longitudinal and vertical vehicle-track interactions on the interface mechanical characteristics. Figure 11 illustrates a vehicle-slab track vertical-longitudinal coupled dynamic model which is developed using the framework of vehicletrack coupled dynamics theory [27, 28], in which railrubber pad and track slab-CA mortar longitudinal interface interactions are further considered by introducing longitudinal degrees of freedom of the vehicle and slab track subsystems [29]. Such a large-scale dynamics model involving many nonlinear factors and time-varying parameters is solved by a new fast explicit integration method proposed by Zhai [30] with a time step size of $1 \times 10^{-4} \mathrm{~s}$.

The longitudinal resistance of the fasteners can be essentially regarded as a kind of friction force generated from the interface between the rail and rubber pad, which

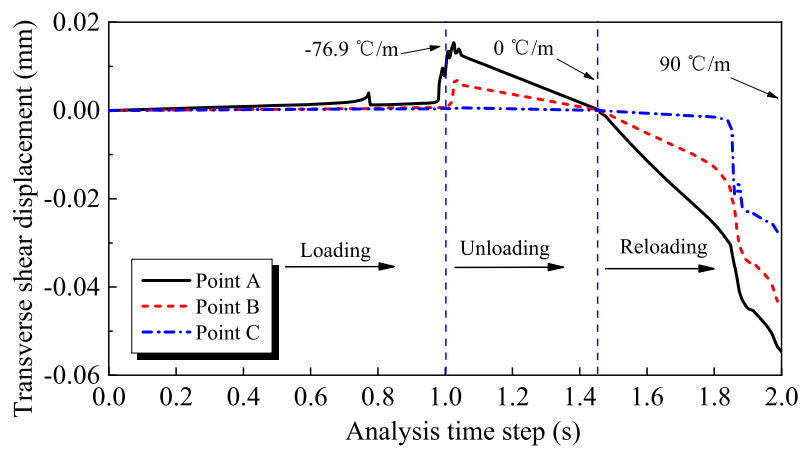

(b)

Fig. 10 Variation characteristics of transverse shear stress and displacement under the cyclic TGL: (a) transverse shear stress and b transverse shear displacement 


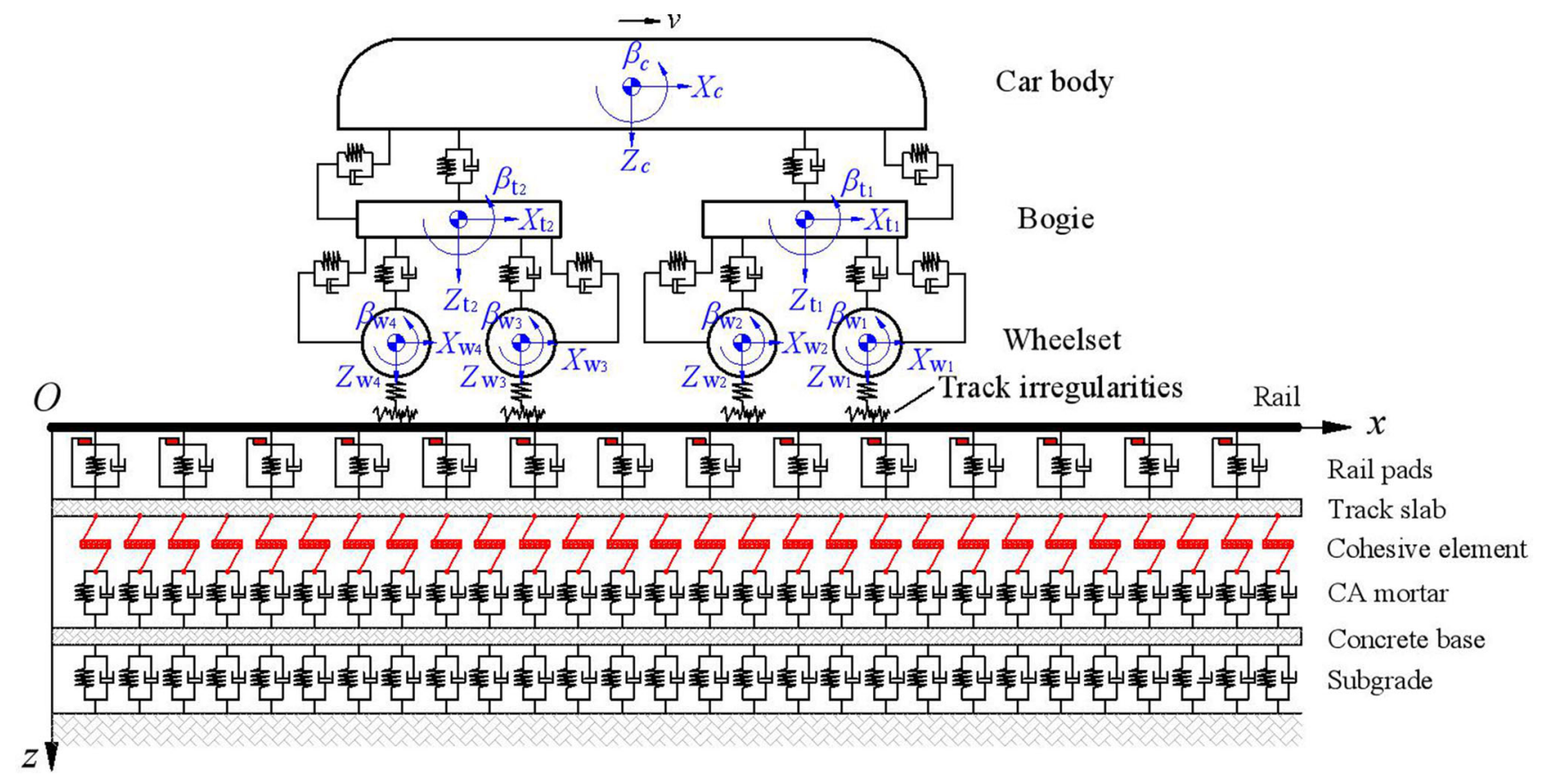

Fig. 11 Vehicle-track vertical-longitudinal coupled dynamics system

can be well characterized by the Dahl friction model [31], based on which the following explicit expressions for the longitudinal resistance are presented:

$$
D\left(t_{j}\right)=\frac{\delta_{\mathrm{tf}}\left(\delta_{\mathrm{t} \max }\left(t_{j}\right)-\delta_{\mathrm{t} 0}\right)}{\delta_{\mathrm{t} \max }\left(t_{j}\right)\left(\delta_{\mathrm{tf}}-\delta_{\mathrm{t} 0}\right)}
$$

$$
\begin{cases}F_{\mathrm{Lf}}(x)=F_{\mathrm{Lfs}} & \text { for } x=x_{\mathrm{s}} \\ F_{\mathrm{Lf}}(x)=F_{\mathrm{Lm}}-\left(F_{\mathrm{Lm}}-F_{\mathrm{Lfs}}\right) \cdot \exp \left(-\frac{\sigma_{0} \cdot\left(x-x_{\mathrm{s}}\right)}{F_{\mathrm{Lm}}}\right) & \text { for } x>x_{\mathrm{S}} \text { or increasing } x, \\ F_{\mathrm{Lf}}(x)=-F_{\mathrm{Lm}}+\left(F_{\mathrm{Lm}}+F_{\mathrm{Lfs}}\right) \cdot \exp \left(\frac{\sigma_{0} \cdot\left(x-x_{\mathrm{S}}\right)}{F_{\mathrm{Lm}}}\right) & \text { for } x<x_{\mathrm{S}} \text { or } \quad \text { decreasing } x\end{cases}
$$

where $F_{\mathrm{Lf}}$ is the fastener longitudinal resistance, $\left(x_{\mathrm{s}}, F_{\mathrm{Lfs}}\right)$ is defined as a reference state and needs to be updated during the motion, and $F_{\mathrm{Lm}}$ denotes the ultimate resistance force of the fasteners.

Considering the fact that the interface damage in the normal mode is negligible under the vertical vehicle dynamic load [12], only the longitudinal shear mode of the cohesive zone model at the track interface was considered in the simulation. The interfacial bond-slip behavior between the track slab and CA mortar is simulated as a series of nonlinear cohesive springs, whose constitutive law follows the bilinear discrete cohesive zone model. The damage variable $D$ is adopted to describe the softening process and track the extent of damage accumulated at the interface. For the $j$ th $(j=1,2, \ldots)$ time step $t_{j}$, it can be expressed as where $\delta_{\mathrm{t} \text { max }}$ refers to the maximum effective displacement attained during the loading history; $\delta_{\mathrm{t} 0}$ denotes the effective displacement at damage initiation; and $\delta_{\mathrm{tf}}$ denotes the effective displacement at complete failure. Considering the irreversibility of damage, the nonlinear longitudinal cohesive force can be calculated by

$F_{\mathrm{t}}\left(\delta_{\mathrm{t}}\left(t_{j}\right)\right)= \begin{cases}k_{\mathrm{t}} \delta_{\mathrm{t}}\left(t_{j}\right) & \delta_{\mathrm{t} \max }\left(t_{j}\right)<\delta_{\mathrm{t} 0} \\ k_{\mathrm{t}}\left(1-D\left(t_{j}\right)\right) \delta_{\mathrm{t}}\left(t_{j}\right) & \delta_{\mathrm{t} 0} \leq \delta_{\mathrm{t} \max }\left(t_{j}\right)<\delta_{\mathrm{tf}} \\ 0 & \delta_{\mathrm{t} \max }\left(t_{j}\right) \geq \delta_{\mathrm{tf}}\end{cases}$

where $k_{\mathrm{t}}$ is the initial stiffness of the cohesive spring without damage, defined by $k_{\mathrm{t}}=F_{\mathrm{tm} /} \delta_{\mathrm{t} 0}$; and $F_{\mathrm{tm}}$ is the interfacial shear strength. 


\subsection{Nonlinear dynamic characteristics of the track interface}

In the simulation, a motor car accelerating from 0 to $250 \mathrm{~km} / \mathrm{h}$ under the combined excitation of track random irregularities and traction torques is investigated. Figure 12 shows the traction characteristic curve of a typical highspeed train in China, which is the total traction force of this train with respect to running speeds. The track irregularity characterized by wavelengths between $0.1-120 \mathrm{~m}$ is assumed to move backward at the vehicle running speed to simulate the vehicle traveling along the track. Without loss of generality, the shear strength of the cohesive element is set as $0.015 \mathrm{MPa}$, the damage initiation displacement in sliding direction is selected as $0.02 \mathrm{~mm}$, and the failure displacement in sliding direction is set as $2.0 \mathrm{~mm}$ in the current simulation.

The wheel-rail interaction forces are portrayed in Fig. 13, from which one can observe that the maximum amplitude of wheel-rail vertical force increases from 54.2 to $83.3 \mathrm{kN}$ during the vehicle acceleration process due to the combined effect of running speed and track irregularities. Regarding the longitudinal counterpart, it increases rapidly once the driving torque acts on the wheel axle and reaches the peak value of $11.01 \mathrm{kN}$ at $2.35 \mathrm{~km} / \mathrm{h}$. As the running speed continues to increase, the amplitude of wheel-rail longitudinal force decreases gradually, which is basically coincident with the variation trend of the traction characteristic curve as depicted in Fig. 12.

Figure 14 illustrates the evolution of damage at the track slab-CA mortar interface during the speed-up process. It should be noted that the coordinate origin in Fig. 14a, b is fixed at the track slab beneath the centroid of the car body. It can be observed that the interface damage occurs in the vicinity of the four wheel loading positions. The maximum damage variable is found to be 0.243 and the corresponding evolution process is displayed in Fig. 14c. As can be seen, the interface damage initiates at $188 \mathrm{~km} / \mathrm{h}$, undergoes rapid propagation at around $226 \mathrm{~km} / \mathrm{h}$, and eventually maintains

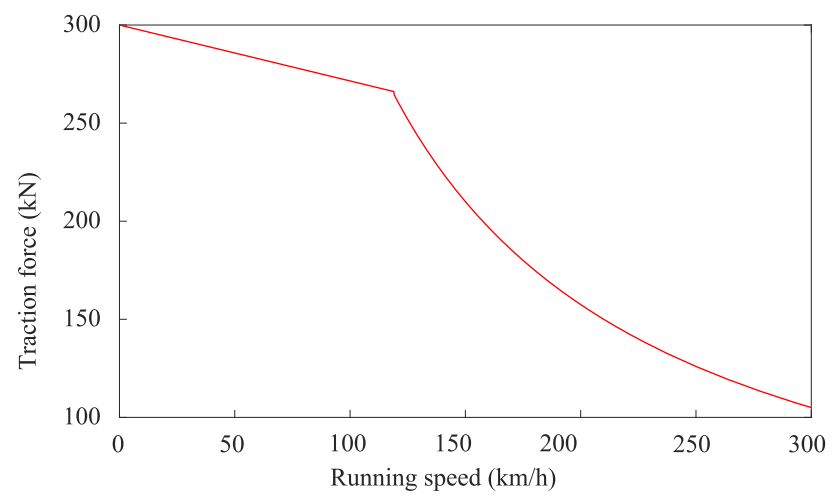

Fig. 12 Traction characteristic curve of a high-speed train

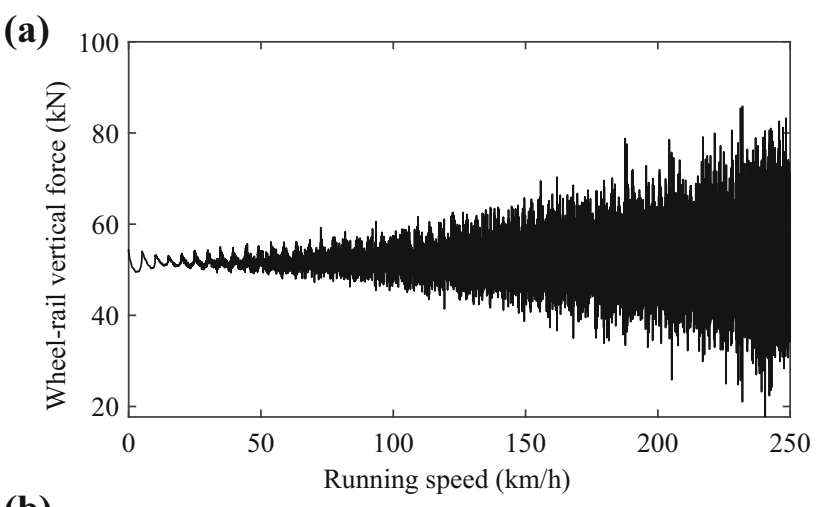

(b)

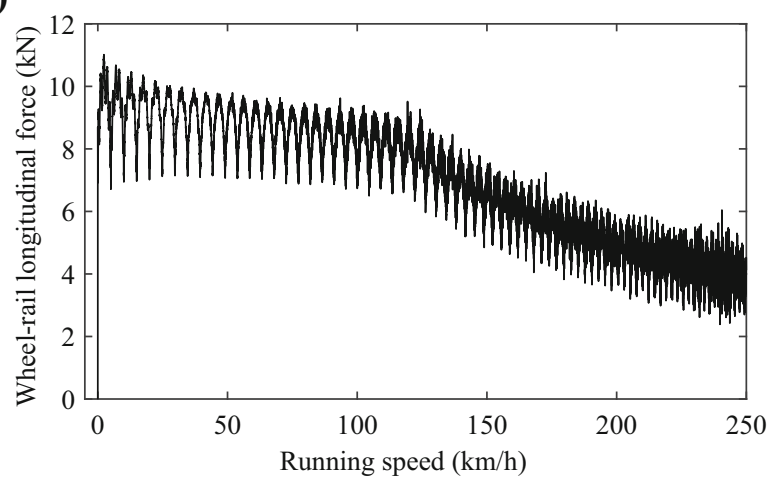

Fig. 13 Variations of wheel-rail interaction forces with increasing speed: a vertical force and $\mathbf{b}$ longitudinal force

the maximum value after the running speed exceeds $232 \mathrm{~km} / \mathrm{h}$.

Therefore, it can be concluded that the coupling of longitudinal and vertical vehicle dynamic loads under the combined effect of track random irregularities and driving torques could result in interface damage at the track interface layers, which should be seriously addressed in high-speed railway engineering practices, particularly in complex mountain areas.

\section{Effect of dynamic water pressure on interface mechanical property}

The engineering practice has shown that the dynamic water pressure at track interface induced by vehicle dynamic loads may play an important role in the expansion of the interface cracks between ballastless track layers. The crack growth rate at the track interface is faster in the areas with abundant rainfall or poor drainage. This is due to the fact that the interface damage will be accelerated by the dynamic water pressure induced by vehicle dynamic load once the rain water penetrates into the interface gap of ballastless tracks. The coupling effect between the interface water and the track slab is mainly reflected in two aspects. On the one hand, the movement of the track slab 


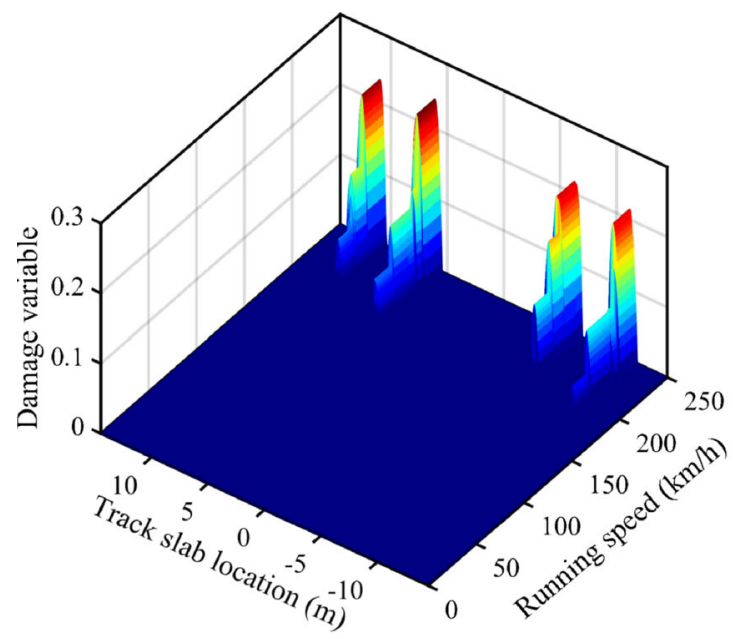

(a)

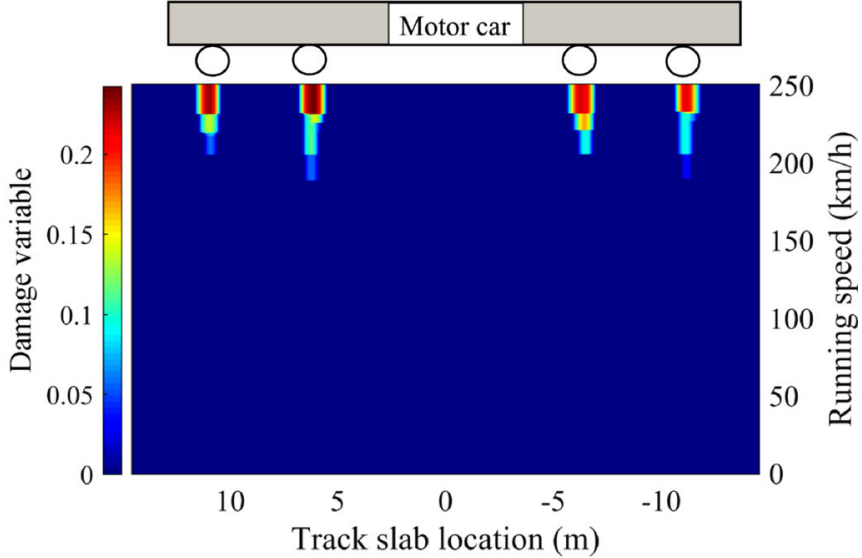

(b)

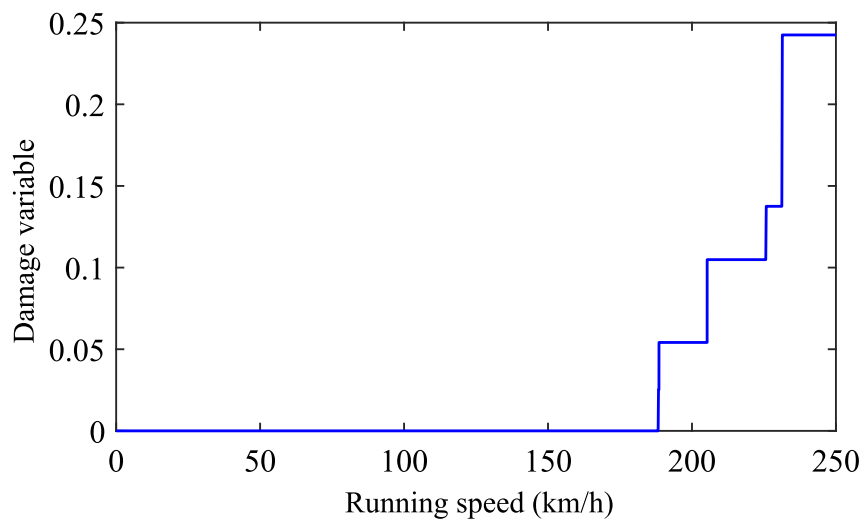

(c)

Fig. 14 Damage at the track interface: a three-dimensional view of time histories and distribution, $\mathbf{b}$ two-dimensional view of time histories and distribution, and $\mathbf{c}$ evolution of the maximum damage variable

under vehicle dynamic loads will squeeze the interface water and thus generate dynamic water pressure; on the other hand, the dynamic water pressure reacts to the track slab, resulting in the normal interface stress and damage development. In this section, the mechanical characteristics and damage behavior at the interface of the double-block ballastless track subject to the vehicle load-induced dynamic water pressure is investigated by fluid-solid coupling method.

\subsection{Modeling of dynamic water pressure}

To solve the fluid-solid coupling problem, the separation method needs to obtain the responses in the solid region and the fluid region, respectively, as well as the data exchange of the fluid-solid coupling interface. For general compressible Newtonian fluid, the laws of physical conservation to follow include the mass conservation law, the momentum conservation law, and the energy conservation law. On this basis, a calculation model of the dynamic water pressure of the track interface is established as shown in Fig. 15, where the upper, lower and end surfaces of the interface gap are set as the fluid-solid coupling interface.

The turbulence influence is considered due to the highfrequency vehicle load and the complicated flow of interface water. The RNG (renormalization group) $k-\varepsilon$ turbulence model is employed in the simulation as it can consider the effects of the separation flow and vortex flow and predict the near-wall flow accurately. The time history of vertical rail supporting forces obtained by the vehicletrack coupled dynamics model is applied to the top of the track slab, and the fixed constraint is applied to the bottom of the support layer. The element size of the track model is smaller than $5 \mathrm{~mm}$, and the total number of elements is about 76,000. The pressure at the opening end of the interface water is set as 0 , and the dynamic viscosity of 


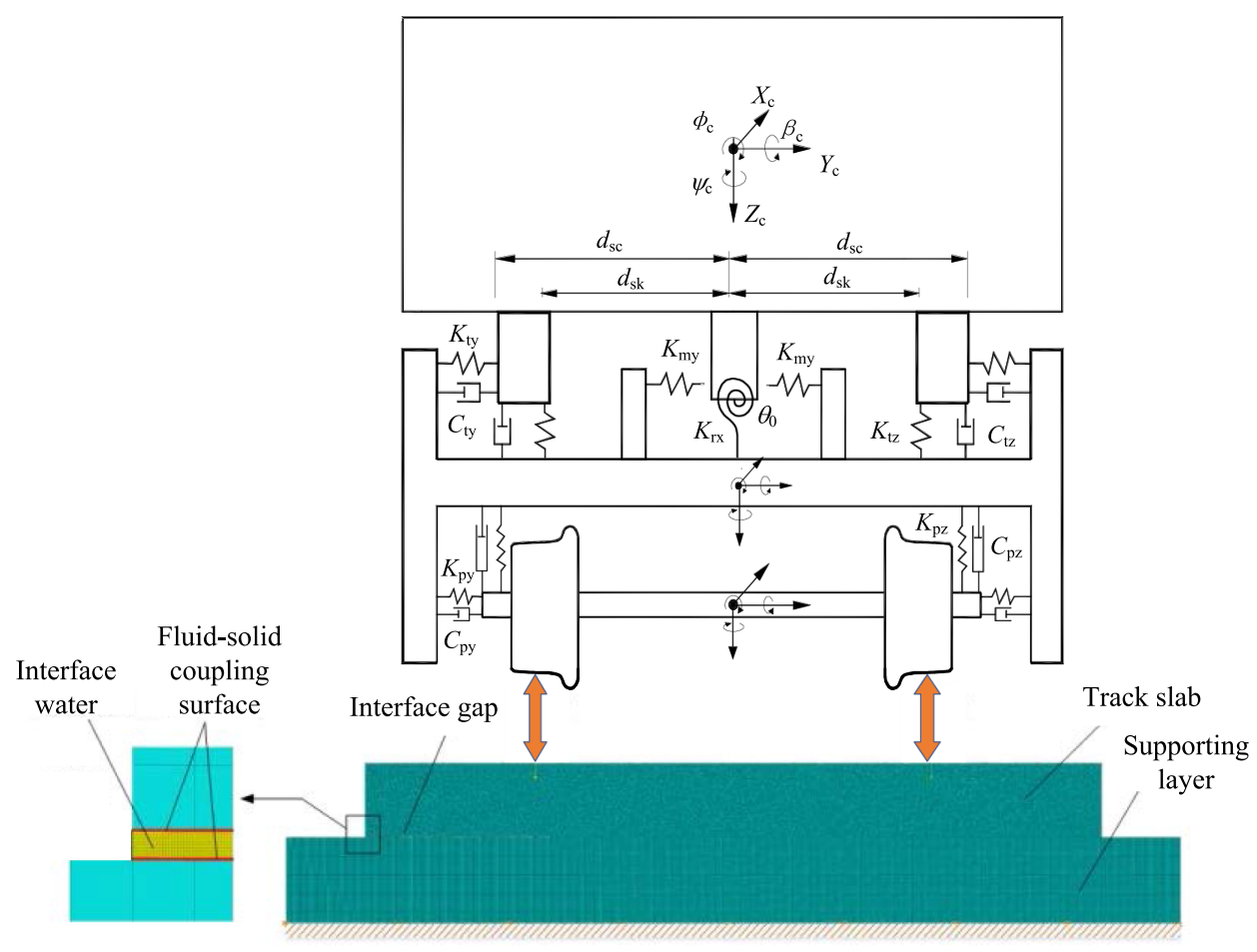

Fig. 15 Calculation model of the dynamic water pressure of the track interface induced by vehicle dynamics load

water is selected as $1.01 \times 10^{-3} \mathrm{~Pa} \cdot \mathrm{s}$. The same integration time step should be used for the ballastless track model and the interface water model, and we found that the time step of $2 \times 10^{-5} \mathrm{~s}$ could enable a satisfied accuracy of simulation results.

\subsection{Spatial and temporal characteristics of dynamic water pressure at the interface}

Take the interface gap with a height of $2 \mathrm{~mm}$ and a depth of $0.7 \mathrm{~m}$ as an example; the time-varying characteristics of the dynamic water pressure due to the vehicle passing at a speed of $350 \mathrm{~km} / \mathrm{h}$ is obtained, as shown in Fig. 16.

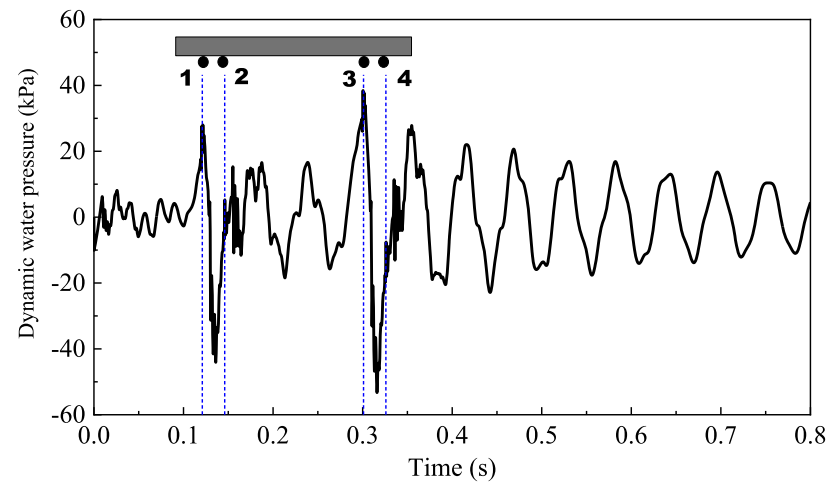

Fig. 16 Time-varying characteristics of dynamic water pressure due to the vehicle passing at a speed of $350 \mathrm{~km} / \mathrm{h}$
As can be seen, when the first wheelset is close to the monitoring section, the dynamic water pressure presents a small fluctuation with an amplitude of $\pm 10 \mathrm{kPa}$. And it rises rapidly to the maximum value when the first wheelset moves at the monitoring section. Subsequently, the dynamic water pressure decreases sharply and forms a negative water pressure, which finally reduces to a minimum value when the mid-point of bogie reaches the monitoring section. As the second wheelset is approaching the monitoring section rapidly, the dynamic water pressure increases significantly, but it can not reach the pressure value as the first wheelset passing through. The dynamic water pressure exhibits the maximum positive value when the third wheelset moves at the section, and the maximum negative value is generated when the mid-point of the second bogie arrives at the section. After the high-speed vehicle passing, the dynamic water pressure continues to oscillate and gradually decreases.

The maximum positive and negative values of the dynamic water pressure at the interface crack tip are obtained when the high-speed vehicle passing through the track with different depths of the interface gap, as shown in Fig. 17.

It can be clearly seen that the dynamic water pressure is negligible when the depth of the interface gap is less than $0.3 \mathrm{~m}$. The maximum positive and negative pressures rise slightly when the depth increases from 0.3 to $0.8 \mathrm{~m}$, and they increase rapidly once the depth exceeds $0.8 \mathrm{~m}$. Note 


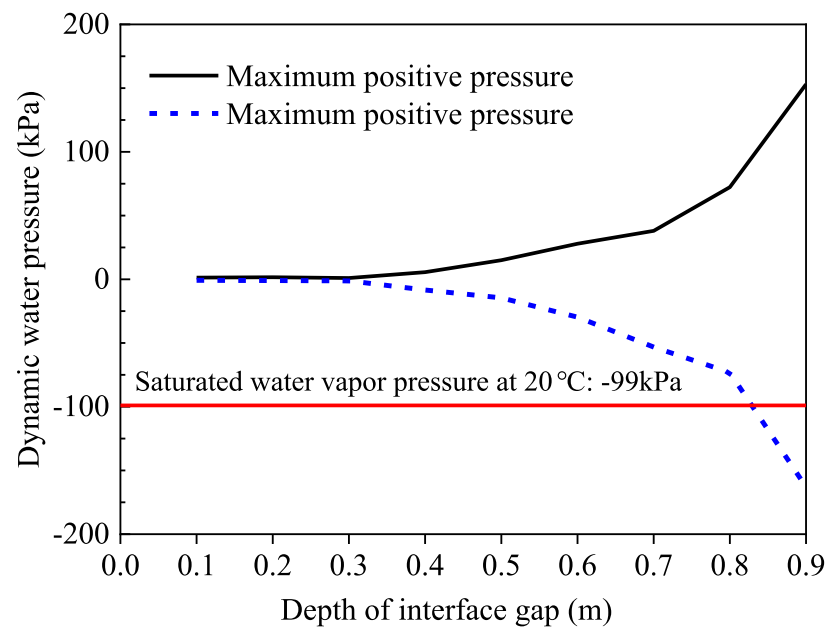

Fig. 17 Maximum positive and negative values of the dynamic water pressure at the interface gap with different depth

that the maximum negative pressure will exceed the saturated water vapor pressure at $20{ }^{\circ} \mathrm{C}$ when the separation depth reaches $0.9 \mathrm{~m}$. At this point, the liquid water will quickly vaporize into steam, causing unfavorable impact and denudation to the concrete materials at the ballastless track interface.

Figure 18 shows the distribution characteristic of the dynamic water pressure along the depth of the track interface gap, together with the contour of the pressure. Here the dynamic water pressure induced by the second bogie passage is taken as an example considering that the dynamic water pressure is found to have the maximum positive value when the third wheelset moves at the monitoring section.

As can be seen, when the third wheelset reaches the monitoring section, the dynamic water pressure is negative within the range of 0.05-0.1 $\mathrm{m}$ away from the gap opening point, while it increases with the gap depth increasing gradually. Overall, the dynamic water pressure at the interface is dominated by positive pressures. A pressure difference is formed between the upper and lower surfaces of the track slab, leading to an upward dynamic force acted on the slab. When the fourth wheelset passes through the section, mainly negative dynamic water pressure is produced by the vehicle dynamic load. The pressure is around $0 \mathrm{kPa}$ in the range of $0.43-0.64 \mathrm{~m}$ from the gap opening point. The track bed plate bears the resultant force of the atmospheric pressure and the dynamic water force. Note that the variation time of the dynamic water pressure is about $0.014 \mathrm{~s}$, and its significant change in a short time indicates that the track slab is subject to a high-frequency force due to the dynamic water pressure, and the force change its direction promptly.

\subsection{Nonlinear mechanical properties of the track interface}

Figure 19 exhibits the variation of the interface normal stress under the vehicle dynamic load. With the fast approaching of high-speed vehicles to the monitoring section, the dynamic water pressure at the track interface increases rapidly, and it reaches the maximum negative value when the middle point of the first bogie passes, while the interface normal stress does not have an obvious change. When the second wheelset passes through the section, the interface normal stress attains its maximum negative value, and then quickly returns to the vicinity of zero with large amplitude fluctuations. The interface stress variation due to the second bogie passing has the same characteristic as that induced by the first bogie, and it oscillates with a certain amplitude after the fourth wheelset passing. It is worth pointing out that this maximum negative value of the interface stress is generated by the fourth wheelset passing, and its maximum positive value occurs at the time $t_{0}$ after the vehicle passes. It can be concluded that the maximum water pressure will be induced when the

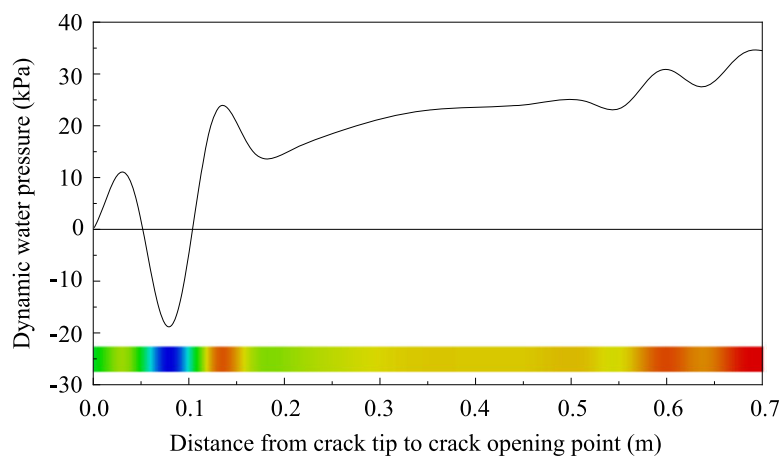

(a)

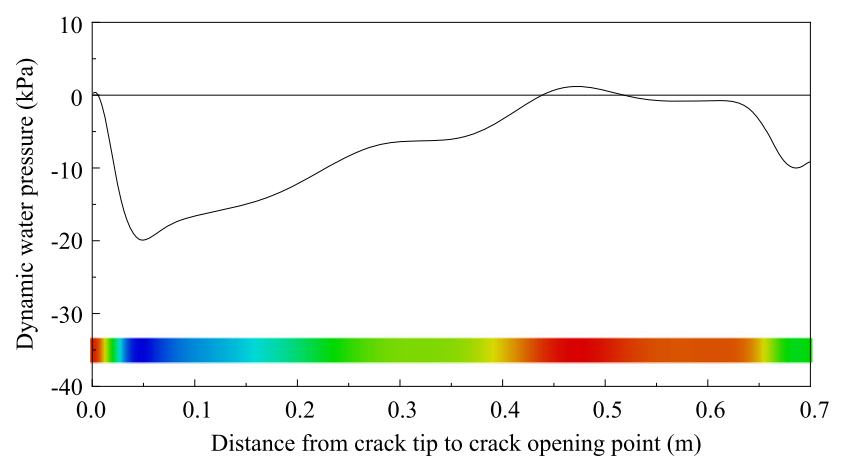

(b)

Fig. 18 Spatial distribution characteristic of the dynamic water pressure at the track interface gap: a the third wheelset passing and $\mathbf{b}$ the fourth wheelset passing 


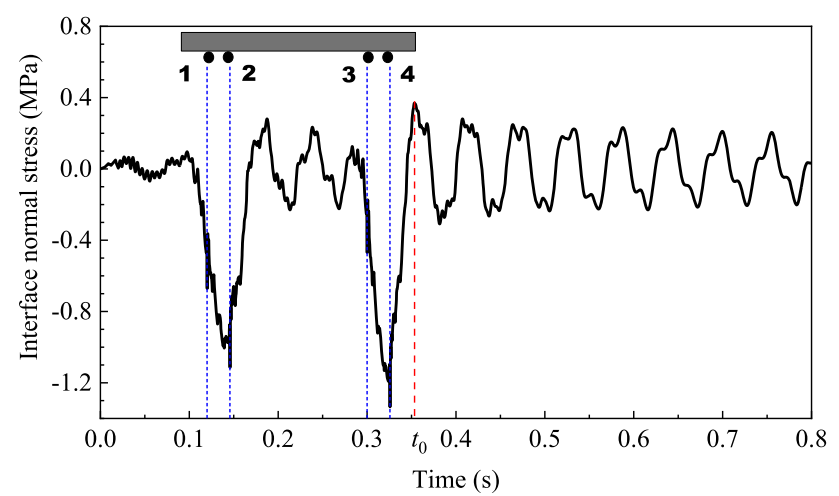

Fig. 19 Variation of interface normal stress under vehicle dynamic load

vehicle passes directly above the interface; however, the maximum positive value of interface normal stress appears after the vehicle passes due to the oscillation of the dynamic water pressure at the interface gap. Therefore, it should be noted that the interface normal stress could be caused by the coupled effect of the vehicle dynamic loads and dynamic water pressure, which will lead to the impact failure or fatigue failure of ballastless track interface, as will be discussed below.

To illustrate the influence of the interface gap depth, the maximum normal stress of the track interface is calculated under different depths of the interface gap, while the other parameters keep unchanged.

As shown in Fig. 20, the maximum positive and negative values of the interface normal stress increase gradually with the increase in the interface gap depth. This is due to the fact that the dynamic water pressure increases with an increase in the gap depth, and its effect on the upward movement of the track slab will be also gradually enhanced, resulting in an increase in the positive interface stress. After the interface gap is further propagated, the

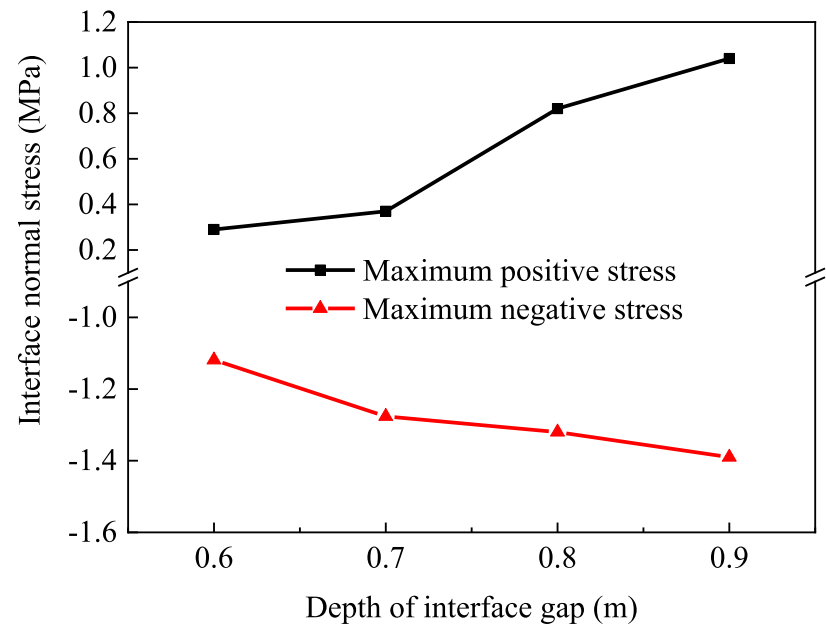

Fig. 20 Influence of interface gap depth bonding area at the interface will be reduced, namely the contact area of vehicle dynamic load transferring to the supporting layer will decrease gradually, leading to a more concentrated interface pressure. That is, the negative interface stress will correspondingly increase.

Similarly, the maximum stress of the track interface is obtained under different heights of the interface gap, in order to reveal the influence of the gap height on the interface mechanical behavior. It can be clearly seen from Fig. 21 that the maximum positive and negative values of interface normal stress decrease gradually with the interface gap height increasing. This is mainly attributed to the fact that the dynamic water pressure decreases as the gap height increases, which leads to a reduced effect of the dynamic water pressure on the track slab, and the maximum values of the interface stress are gradually closer to those without interface water.

It is also found that the interface failure at material points would occur due to the coupled dynamic effect of vehicle load and water pressure under the condition that the interface gap depth reaches $0.9 \mathrm{~m}$, the gap height is $2 \mathrm{~mm}$, and the vehicle speed is $350 \mathrm{~km} / \mathrm{h}$. Figure 22 shows the time varying characteristic of the interface damage when the vehicle is passing through the section. Note that here the mechanical parameters of the cohesive zone model are the same as those in Sect. 3.

As can be seen, there are obviously two damage development stage with instantaneous jumps. The damage level jumps from 0 to 0.72 at time step $t_{1}$ after the first bogie passing. Subsequently, the damage level remains at 0.72 until it jumps to 1 at the time step $t_{2}$ after the second bogie passing, and the complete failure at the current material point occurs as the damage level increases to 1 . It is worth pointing out that the time of interface material failure is consistent with the time when the interface stress reaches the maximum value after the second bogie passes

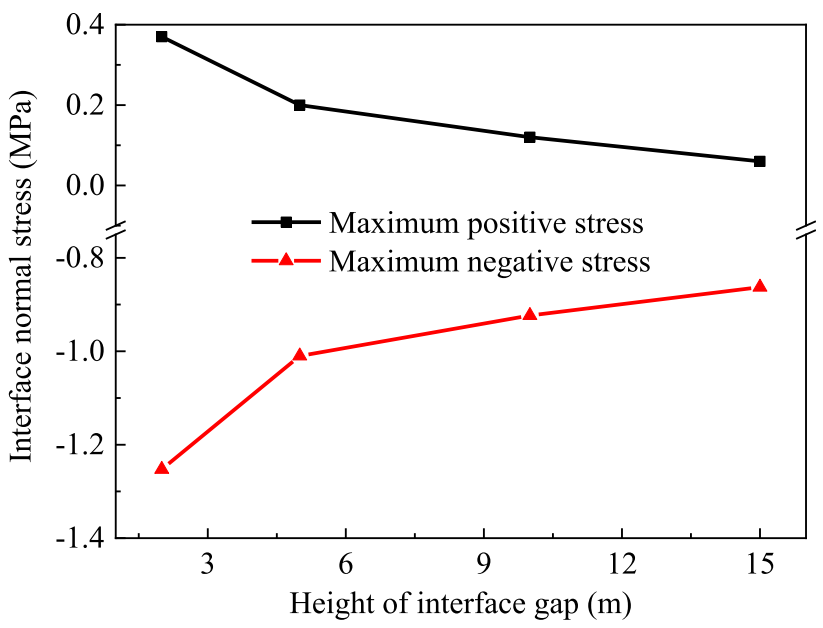

Fig. 21 Influence of interface gap height 


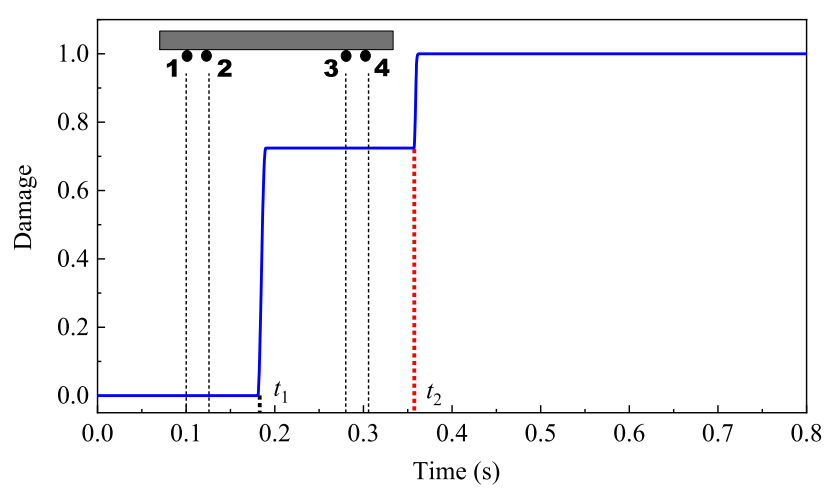

Fig. 22 Interface damage evolution when the vehicle is passing through the section

(see Fig. 19). The interface material failure happens in a very short time, which indicates the brittle fracture characteristics of the track interface.

\section{Conclusions}

In this work, the effect of train-track interaction and environmental loads on the mechanical characteristic variation at the interface between track layers of ballastless tracks in high-speed railway has been investigated and discussed systematically. A bilinear cohesive zone model considering mixed-mode damage has been employed in a finite element model of a double-block ballastless track to study the effect of loading-unloading processes of the negative and positive TGLs on the mechanical behavior of the track interface. Further, the effect of wheel-rail longitudinal interactions on the nonlinear dynamic characteristics of the track interface has been illustrated by using a vehicle-slab track vertical-longitudinal coupled dynamics model. Finally, the coupled dynamic effect of vehicle load and water pressure on the mechanical characteristics and damage evolution of the track interface has been revealed using a fluid-solid coupling method. The main findings can be summarized as follows:

(1) The loading history of the loading-unloading process of the positive and negative TGLs has a significant influence on the mechanical variation of the track interface. With the unloading of the negative TGL, the interface stress decreases gradually but the interface damage continues to increase. The followed loading of the positive TGL will lead to the further propagation of the interface crack, and the ability to resist interface damage under the positive TGL will be greatly reduced after the interface separation induced by the former loading-unloading process of negative TGL.
(2) The shapes of the track interface gap are quite different under the negative and positive TGLs, and the stress, displacement and damage laws at different positions of the track interface show different nonlinear variation patterns. The depth variation of the interface gap under different TGLs exhibit strong nonlinear characteristics. The TGL of track slabs that causes rapid damage development should be avoided in practical application in order to prevent the early damage of the track interface.

(3) The coupling of longitudinal and vertical dynamic loads of a vehicle under the combined effect of track random irregularities and driving torques could result in interface damage between track slab and CA mortar in the vicinity of the four wheel loading positions. For evolution of the maximum damage variable obtained in this paper, it initiates at $188 \mathrm{~km} / \mathrm{h}$, undergoes rapid propagation at around $226 \mathrm{~km} / \mathrm{h}$, and eventually maintains the maximum value after the running speed exceeds $232 \mathrm{~km} / \mathrm{h}$.

(4) The dynamic water pressure presents different spatial distribution characteristic along the interface gap when different wheelsets passing through, and its significant change in a short time indicates a high frequency force acting on the track slab. Under the calculated conditions, the maximum water pressures rise gently when the interface gap depth increases from 0.3 to $0.8 \mathrm{~m}$, whereas they increase rapidly when the depth exceeds $0.8 \mathrm{~m}$.

(5) The dynamic water pressure exhibits peak values when the vehicle passes directly above the track interface. However, the maximum positive value of interface normal stress appears after the vehicle passage due to the oscillation of the dynamic water pressure at the interface gap, which could lead to impact failure or fatigue failure at ballastless track interface. The maximum interface stress gradually increases with the increase in the interface gap depth, while it gradually decreases with the increase in the interface gap height.

Acknowledgements This work was supported by the National Natural Science Foundation of China (Nos. 51708457, 11790283, and 51978587), the Fund from State Key Laboratory of Traction Power (2019TPL-T16), the Young Elite Scientists Sponsorship Program by CAST (2018QNRC001), and the 111 Project (Grant No. B16041), which is gratefully acknowledged by the authors.

Open Access This article is licensed under a Creative Commons Attribution 4.0 International License, which permits use, sharing, adaptation, distribution and reproduction in any medium or format, as long as you give appropriate credit to the original author(s) and the source, provide a link to the Creative Commons licence, and indicate if changes were made. The images or other third party material in this article are included in the article's Creative Commons licence, unless 
indicated otherwise in a credit line to the material. If material is not included in the article's Creative Commons licence and your intended use is not permitted by statutory regulation or exceeds the permitted use, you will need to obtain permission directly from the copyright holder. To view a copy of this licence, visit http://creativecommons. org/licenses/by/4.0/.

\section{References}

1. Gautier PE (2015) Slab track: review of existing systems and optimization potentials including very high speed. Constr Build Mater 92:9-15

2. Matias SR, Ferreira PA (2020) Railway slab track systems: review and research potentials. Structu Infrastructu Eng 16(12):1635-1653

3. Zhao G, Gao L, Zhao L, Zhong Y (2017) Analysis of dynamic effect of gap under CRTS II track slab and operation evaluation. J China Railw Soc 39(1):1-10 (in Chinese)

4. Zhong Y, Gao L, Zhang Y (2018) Effect of daily changing temperature on the curling behavior and interface stress of slab track in construction stage. Constr Build Mater 185:638-647

5. Zhang Y, Cai X, Gao L, Wu K (2019) Improvement on the mechanical properties of $\mathrm{CA}$ mortar and concrete composite specimens in high-speed railway by modification of interlayer bonding. Constr Build Mater 228:116758

6. Peng H, Zhang Y, Wang J, Liu Y, Gao L (2019) Interfacial bonding strength between cement asphalt mortar and concrete in slab track. J Mater Civ Eng 31(7):1-11

7. Wang J, Zhou Y, Wu T, Wu X (2019) Performance of cement asphalt mortar in ballastless slab track over high-speed railway under extreme climate conditions. Int J Geomech 19(5):1-11

8. Yu Y, Tang L, Ling X, Cai D, Ye Y, Geng L (2020) Mitigation of temperature-induced curling of concrete roadbed along highspeed railway: in situ experiment and numerical simulation. KSCE J Civil Eng 24(4):1195-1208

9. Chen R, Yang K, Qiu X, Zeng X, Wang P, Xu J, Chen J (2017) Degradation mechanism of CA mortar in CRTS I slab ballastless railway track in the Southwest acid rain region of China-Materials analysis. Constr Build Mater 149:921-933

10. Cai X-P, Luo B-C, Zhong Y-L, Zhang Y-R, Hou B-W (2019) Arching mechanism of the slab joints in CRTSII slab track under high temperature conditions. Eng Fail Anal 98(2018):95-108

11. Li Y, Chen J, Wang J, Shi X, Chen L (2020) Study on the interface damage of CRTS II slab track under temperature load. Structures 26:224-236

12. Zhu S, Cai C (2014) Interface damage and its effect on vibrations of slab track under temperature and vehicle dynamic loads. Int $\mathrm{J}$ Non-Linear Mech 58:222-232

13. Zhu S, Wang M, Zhai W, Cai C, Zhao C, Zeng D, Zhang J (2018) Mechanical property and damage evolution of concrete interface of ballastless track in high-speed railway: experiment and simulation. Constr Build Mater 187:460-473
14. Ren J, Wang J, Li X, Wei K, Li H, Deng S (2020) Influence of cement asphalt mortar debonding on the damage distribution and mechanical responses of CRTS I prefabricated slab. Constr Build Mater 230:116995

15. Zhao P, Liu X, Yang R, Guo L, Hu J (2016) Experimental study of temperature load determination method of bi-block ballastless track. J China Railw Soc 38(1):92-97 (in Chinese)

16. Zhang Y, Wu K, Gao L, Yan S, Cai X (2019) Study on the interlayer debonding and its effects on the mechanical properties of CRTS II slab track based on viscoelastic theory. Constr Build Mater 224:387-407

17. Xiao H, Zhang Y-R, Li Q-H, Jin F, Nadakatti MM (2019) Analysis of the initiation and propagation of fatigue cracks in the CRTS II slab track inter-layer using FE-SAFE and XFEM. Proc Inst Mech Eng F J Rail Rapid Transit 233(7):678-690

18. Cao S, Yang R, Su C, Dai F, Liu X, Jiang X (2016) Damage mechanism of slab track under the coupling effects of train load and water. Eng Fract Mech 163:160-175

19. Zhu S, Cai C, Zhai W (2016) Interface damage assessment of railway slab track based on reliability techniques and vehicletrack interactions. J Transp Eng 142(10):04016041

20. Alfano G, Crisÿeld MA (2001) Finite element interface models for the delamination analysis of laminated composites: mechanical and computational issues. Int $\mathrm{J}$ Numer Methods Eng 50(2000):1701-1736

21. Camacho GT, Ortiz M (1996) Computational modelling of impact damage in brittle materials. Int $\mathrm{J}$ Solids Struct 33(20):2899-2938

22. Geubelle PH, Baylor JS (1998) Impact-induced delamination of composites: a 2D simulation. Compos B Eng 29(5):589-602

23. Needleman A (1990) An analysis of tensile decohesion along an interface. J Mech Phys Solids 38(3):289-324

24. Tvergaard V, Hutchinson JW (1992) The relation between crack growth resistance and fracture process parameters in elasticplastic solids. J Mech Phys Solids 40(6):1377-1397

25. Camanho PP, Davila CG (2002) Mixed-Mode Decohesion Finite Elements for the Simulation of Delamination in Composite Materials. NASA/TM-2002-2117372002. pp 1-37.

26. TB 10621-2014 (2014) Code for Design of High Speed Railway. Beijing: The National Railway Administration of China. (in Chinese).

27. Zhai W (2020) Vehicle-track coupled dynamics: theory and application. Springer, Singapore

28. Zhai W, Wang K, Cai C (2009) Fundamentals of vehicle-track coupled dynamics. Veh Syst Dyn 47:1349-1376

29. Luo J, Zhu S, Zhai W (2020) Theoretical modelling of a vehicleslab track coupled dynamics system considering longitudinal vibrations and interface interactions. Veh Syst Dyn. https://doi. org/10.1080/00423114.2020.1751860

30. Zhai W (1996) Two simple fast integration methods for largescale dynamic problems in engineering, . Int J Numer Meth Eng 39:4199-4214

31. Luo J, Zeng Z (2019) A novel algorithm for longitudinal trackbridge interactions considering loading history and using a verified mechanical model of fasteners. Eng Struct 183:52-68 